\title{
Evaluation of Alpinia galanga (Zingiberaceae) extracts and isolated trans-cinnamic acid on some mosquitoes larvae
}

\author{
Waraporn Poonsri ${ }^{1}$, Anchulee Pengsook ${ }^{2}$, Wanchai Pluempanupat ${ }^{2}$, Thitaree Yooboon ${ }^{1}$ \\ and Vasakorn Bullangpoti ${ }^{*}$ (D)
}

\begin{abstract}
Background: Mosquitoes are vectors for diseases damaging human health and thus, there is an urgent need for insecticidal compounds to control their population. The objective of this study was to determined the efficiency from trans-cinnamic acid isolated from Alpinia galanga (Zingiberales: Zingiberaceae) for control of Aedes aegypti (Dipetera: Culicidae), Anopheles dirus B (Dipetera: Culicidae) and Culex quinquefasciatus (Dipetera: Culicidae).

Methods: Alpinia galanga (Zingiberales:Zingiberaceae) was extracted by soaking in a sequence of solvents (hexane, dichloromethane, ethyl acetate and methanol), and the isolated trans-cinnamic was separated by preparative thin layer chromatography. All crude extracts and isolated trans-cinnamic were evaluated for their control and affect on detoxification enzyme activities of the third-instar larvae of each mosquito species in laboratory conditions.

Results: Our results showed that the hexane crude extract had the best control efficiency in all species, particularly in CX. quinquefasciatus. The trans-cinnamic acid, isolated compound from hexane crude extract showed as active ingredient against third-instar larvae of each mosquito species. Mortality in this case may result from the inhibition of carboxylesterase.

Conclusion: These results indicated that A. galanga which had trans-cinnamic acid as active ingredient compound could represent a promising naturally occurring control agent for all three mosquito species. However, this research consider as an initial prospective study, the other side effect on nontarget species need to concerned before used as commercial product.
\end{abstract}

Keywords: Alpinia galanga, Aedes aegypti, Anopheles dirus B, Culex quinquefasciatus, Detoxification enzymes, Acetylcholinesterase

\section{Background}

Mosquitoes are carriers of diseases causing serious health problems in tropical regions. A variety of mosquito species transmit many diseases to humans and animals in a species-dependent manner; for example, Aedes aegypti is the vector for dengue fever, Zika fever and Chikungunya, Anopheles dirus B is a vector for malaria in Asian

\footnotetext{
*Correspondence: fscivkb@ku.ac.th

${ }^{1}$ Animal Toxicology and Physiology Speciality Research Unit, Department of Zoology, Faculty of Science, Kasetsart University, Phahonyothin Road, Bangkok 10900, Thailand

Full list of author information is available at the end of the article
}

forested zones and Culex quinquefasciatus is a vector for zoonotic diseases that affect humans and wild and domestic animals. Almost all these diseases are severe problems in many countries, which makes it necessary to control mosquito populations. Although there are many mosquito pesticides available on the market currently, mosquitoes can develop resistance to pesticides, especially synthetic pesticides, and thus, it becomes necessary to increase the dosage used to control mosquitoes, introducing additional risks to human health and to the environment.

The previous studies found that one of the important mechanisms for insecticide resistance is by the increasing 
of detoxification enzymes activities, including carboxylesterase (CarE) and glutathione-S-transferase (GST) [13, $18,40]$. Many reports showed mosquitoes using detoxification enzymes and become resistant to many synthetic pesticides [21, 24, 25]. Alternative ways are required to counteract insecticide resistance development.

Acetylcholinesterase (AChE) plays a crucial act for every function of living being including insects. AChE catalyses the hydrolysis of acetylcholine, a neurotransmitter for cholinergic neurotransmission in insects. Most of current insecticides such as organophosphorus is based on inhibiting AChE by hydrolyse the neurotransmitter acetylcholine to terminate neuronal excitement at the postsynaptic membrane [11]. In mosquitoes, resistance is usually caused by less inhibition of the target enzyme in the resistant strains $[2,28,41]$. The understanding of the pesticide action on enzymes in insect pests should enable to produce selective and effective insecticides with low mammalian toxicity (Arshia et al. 2016).

From the past, the discovery and development of pesticides with mosquito larval toxicity derived from plant extracts have become a topic of interest to many researchers. At present, plant extract products are attractive choices for use in integrated pest management programmes to reduce the residues in the environment as it has biodegradable efficiency. Many studies have used plant extracts to control mosquitoes, such as the essential rhizome oil of Blumea mollis or Piper retrofractum against $C x$. quinquefasciatus larvae [5, 37], Curcuma aromatica or Dalbergia oliveri to control Ae. aegypti [7, 33]. In addition, Cymbopogon proximus, Lippia multiflora and Ocimum canum have been used against Ae. aegypti and A. gambiae [3]; Juniperus macropoda and Pimpinella anisum against $A$. stephensi, Ae. aegypti and $C x$. quinquefasciatus [34]; Citrus bergamia, Cuminum myrrha and Pimenta racemosa against Ae. aegypti and $C x$. pipiens pallens [23] and Chloroxylon swietenia against Ae. aegypti and A. stephensi [20]. In addition, essential oils of Cyperus rotundus, Alpinia galanga and Cinnamomum verum, were found to synergistic activity with permethrin or repellent against Ae. aegypti [6, 27].

This present study evaluated the use of rhizome Alpinia galanga, a herb in the Zingiberaceae family that is commonly used in cooking, especially in Thai cuisines, to control three species of mosquito larvae. Previous research has shown that plants belonging to the Zingiberaceae family, including Curcuma xanthorrhiza, Curcuma zedoaria, Kaempferia galanga and Kaempferia pandurata, showed toxicity to Spodoptera littoralis [31]. This present study was focused on analysing and comparing the rhizome of $A$. galanga toxicity in Ae. aegypti, $A$. dirus $\mathrm{B}$ and $C x$. quinquefasciatus larvae under laboratory conditions. We chose the rhizome of $A$. galanga for this research because it is easily found and grown in Thailand or other countries in SE Asia; thus, it could probably be used easily throughout the year and provide a low-cost form of mosquito control. The development and use of locally available plants is an alternative strategy for the control of mosquito would cause the decreasing use of conventional synthetic pesticides. Additionally, the activities of detoxification enzymes (CarE and GST) and $\mathrm{AChE}$ activities were. Knowing the mechanism of action will help to control the resistance in insects' pests, which is an increasing problem in insect control.

\section{Materials and methods \\ Mosquito culture}

Egg clusters of Ae. aegypti, Anopheles dirus B and Cx. quinquefasciatus Thailand laboratory strains were received from the Ministry of Public Health, Nonthaburi province, Thailand. The larvae were reared in plastic boxes (size $50 \times 30 \mathrm{~cm}$ ) with net covers. The larvae were reared in an insect room with artificial fish diet and a controlled rearing environment of $28{ }^{\circ} \mathrm{C}, 70 \%$ relative humidity $(\mathrm{RH})$ and 14:10 of dark:light (D:L) photoperiod without xenobiotic exposure at the Department of Zoology, Faculty of Science, Kasetsart University. Third-instar larvae were used for larvicidal efficiency testing.

\section{Plant materials}

The rhizomes of $A$. galanga were collected from Nonthaburi province, Thailand, in May 2017, and subsequently, rhizomes were removed and sliced. The sliced rhizomes were shade-dried by a hot air oven at $60{ }^{\circ} \mathrm{C}$ for 3 days. The dried plant material was powdered in a blender at the Faculty of Forestry, Kasetsart University, Bangkhean Campus, Thailand. The powder was stored in zip-lock bags in a refrigerator at $4{ }^{\circ} \mathrm{C}$ to prevent sample contamination.

\section{Plant extraction}

The dry A. galanga rhizome powder (1 kg) was extracted sequentially with 41 of hexane, dichloromethane, ethyl acetate and methanol by soaking the plant material at room temperature for 7 days. Each crude extract was filtered through filter paper (Whatman No. 1) using a vacuum pump and dried using a rotary evaporator (IKA model RV 10 basic, Thailand) and then stored at $4{ }^{\circ} \mathrm{C}$ before use in the experiments.

The most active hexane extract $(200 \mathrm{mg}$ ) was subjected to preparative thin layer chromatography $(L \times W$ $20 \mathrm{~cm} \times 20 \mathrm{~cm}$, Silica gel 60 PF254 for preparative thin layer chromatography, Merck) and eluted with $20 \%$ EtOAc in hexane to obtain three fractions. Due to their polarity, fraction 3 was first chosen to purify by 
preparative thin layer chromatography using 50\% EtOAc in hexane. One isolated compound was identified as trans-cinnamic acid white solid $(0.5 \mathrm{mg}, 0.25 \%)$ by spectral analyses. The ${ }^{1} \mathrm{H}$ and ${ }^{13} \mathrm{C}$ NMR spectra were recorded on a Bruker $400 \mathrm{MHz}$ AVANCE III HD spectrometer operating at $400 \mathrm{MHz}\left({ }^{1} \mathrm{H}\right)$ and $100 \mathrm{MHz}\left({ }^{13} \mathrm{C}\right)$.

trans-Cinnamic acid white solid; ${ }^{1} \mathrm{H}$ NMR $(400 \mathrm{MHz}$, $\left.\mathrm{CDCl}_{3}\right): \delta 7.84(\mathrm{~d}, J=16.0 \mathrm{~Hz}, 1 \mathrm{H}), 7.60-7.58(\mathrm{~m}, 2 \mathrm{H})$, $7.46-7.43(\mathrm{~m}, 3 \mathrm{H})$ and $6.52(\mathrm{~d}, J=16.0 \mathrm{~Hz}, 1 \mathrm{H}) .{ }^{13} \mathrm{C}$ NMR $\left(100 \mathrm{MHz}, \mathrm{CDCl}_{3}\right): \delta 172.4,147.1,134.1,130.8,128.9$, 128.4 and 117.3. The NMR data were consistent with those from Kalinowska et al. [17].

\section{Larvicidal bioassay}

The assays were performed with a slight modification of the standard protocol recommended by the World Health Organization [42] under laboratory conditions. Each plant extract was dissolved in dimethyl sulphoxide (DMSO). To prepare a series of extracts with different concentrations, $0.5 \mathrm{ml}$ of DMSO solution containing the extract compound was wholly mixed with $249 \mathrm{ml}$ of distilled water in a bowl $10 \mathrm{~cm}$ in diameter to give a range of concentrations (0-2000 ppm). Four batches of 25 early third-instar larvae of each mosquito were maintained in $250 \mathrm{ml}$ of aqueous solution, with a final total number of 100 larvae for each concentration. This experiment was conducted under laboratory conditions at $28{ }^{\circ} \mathrm{C}, 70 \%$ RH and 14:10 D:L photoperiod. Temephos were used for positive control in each case. During the experiment, the mosquitoes were not fed. Whereas, positive control used is Temephos. The mosquito larval mortality was recorded as the $\mathrm{LC}_{50}$ values after 24 and $48 \mathrm{~h}$ by Probit analysis using StatPlus version on a Mac (AnalystSoft company, Canada).

\section{Mode of action study}

Third-instar larvae of each mosquito were treated with crude extracts and trans-cinnamic acid compound of $A$. galanga at the $\mathrm{LC}_{50}$ value concentration, and the control group was treated with DMSO (25 larvae/replication). After $24 \mathrm{~h}$ of treatment, the surviving mosquitoes were used for enzyme extraction.

The extraction method was modified from Phankaen et al. [32]. Surviving third-instar larvae of each mosquito were placed in a microtube and kept on ice. After that, thirty larvae was ground with homogenized buffer $[0.1 \mathrm{M}$ potassium phosphate buffer mix with $1 \mathrm{mM}$ ethylenediaminetetraacetic acid (EDTA) at $\mathrm{pH}$ 8.0], then centrifuged (Hettich model Universal $16 \mathrm{R}$, Germany) at $4{ }^{\circ} \mathrm{C}$ and $10,000 \times g$ for $10 \mathrm{~min}$ and the supernatant was transferred to a new tube. The supernatant was centrifuged further at $100,000 \mathrm{~g}$ and $4{ }^{\circ} \mathrm{C}$ for $60 \mathrm{~min}$. The supernatant was used to analyse carboxylesterase (CE), glutathione-S-transferase (GST) and acetylcholinesterase (AChE).

The CE activity was analysed by a para-nitrophenyl acetate (pNPA) assay modified from Phankaen et al. [32]. $50 \mathrm{mM}$ phosphate buffer was mixed with the supernatant, then $10 \mathrm{mM}$ pNPA was added and the solution was measured by kinetic mode at $\lambda_{\max }=410 \mathrm{~nm}$ at $37{ }^{\circ} \mathrm{C}$ using a microplate reader (Biotek PowerWave XS microplate spectrophotometer, USA). The CE activity was determined using an extinction coefficient of 176.4705 for pNPA. Three biological replicates were tested per treatment.

The method for determining GST activity was that of Oppenoorth et al. [30]. The reaction solution contained $100 \mu \mathrm{l}$ of enzyme solution, $200 \mu \mathrm{l}$ of $50 \mathrm{mM}$ potassium phosphate buffer $(\mathrm{pH} 7.3)$ and $10 \mu \mathrm{l}$ of $150 \mathrm{mM}$ 1-chloro-2,4-dinitrobenzene (CDNB). Optical density was recorded at intervals of $30 \mathrm{~s}$ for $3 \mathrm{~min}$ at $37{ }^{\circ} \mathrm{C}$ and $340 \mathrm{~nm}$ with a microplate reader (Biotek PowerWave XS microplate spectrophotometer, US). The GST activity was determined using an extinction coefficient of 0.0096 for CDNB. Three biological replicates were tested per treatment.

The AChE activity analysis method was modified from Ellman et al. [14]. A $100 \mathrm{mM}$ potassium phosphate buffer $\mathrm{pH} 8.0$ was mixed with $50 \mu \mathrm{l}$ supernatant and incubated at $30{ }^{\circ} \mathrm{C}$ for $30 \mathrm{~min}$, then substrates [10 mM of Ellman's reagent (DTNB), $0.1 \mathrm{mM}$ EDTA, $100 \mathrm{mM}$ of acetylthiocholine iodide (ASCh) and $100 \mathrm{mM}$ phosphate buffer ( $\mathrm{pH}$ 7.2)] were added and the solution was measured at $\lambda_{\max }=412 \mathrm{~nm}$ by kinetic mode. The activity was shown by a yellow colour generated by the reaction of DTNB (5, $5^{\prime}$-dithiobis (2-nitrobenzoic acid)) using a microplate reader (Biotek PowerWave XS microplate spectrophotometer, USA), and the AChE activity was converted to $\mathrm{nM}$ of acetylthiocholine hydrolysed per $\min (\varepsilon 412 \mathrm{~nm}=1$. $36 \times 10^{4} \mathrm{M}^{-1} \mathrm{~cm}^{-1}$ ). Three biological replicates were tested per treatment.

A statistical comparison of all enzyme activity was performed using Tukey's test in the StatPlus for Mac programme (AnalystSoft Inc., Canada). The protein content of each fraction used as an enzyme source was determined by the Bradford method [4] before measuring the enzyme activity for the total analysed protein.

\section{Results}

The amount of the extracts obtained from the various solvent extractions are given in Table 1. The methanol crude extract provided the highest amount of extract, whereas dichloromethane gave the lowest amount (Table 1). The acute toxicity of various concentrations of the rhizome of $A$. galanga extracts on the mortality of all 
mosquito larvae showed that the crude hexane extract had the highest toxicity at both 24 and 48 h post-treatment (Table 2). Mortality occurred in a dose-dependent manner, and no mortality was observed in the controls.

The toxicity of trans-cinnamic acid was higher than that of the hexane crude extract (Table 2). Mortality occurred in a dose or time-dependent manner, and no mortality was observed in the controls. Similar to that of the crude extract, the toxicity of trans-cinnamic acid in $C x$. quinquefasciatus larvae was higher than that in other species.

The effects of each crude extract and the active ingredient trans-cinnamic acid on Ae. aegypti showed that the CE was induced in hexane crude extract and transcinnamic acid. GST on Ae. aegypti was induced significantly by all crude extracts and trans-cinnamic acid (Table 3). AchE on Ae. aegypti was induced significantly by all crude extracts; whereas trans-cinnamic acid were reduced (Table 3). The effect of each crude extract and trans-cinnamic acid on $A$. dirus $\mathrm{B}$ showed that the $\mathrm{CE}$ was reduced. However, GST were induced on $A$. dirus $\mathrm{B}$ (Table 3). AchE in A. dirus B almost induced except $A$. dirus B larvae tested on trans-cinnamic acid (Table 3). The enzyme activities in $C x$. quinquefasciatus showed significant reductions for CE and GST, whereas AChE activity was induced in all crude extracts expet larvae tested on trans-cinnamic acid (Table 3).

\section{Discussion}

All three mosquitoes chosen for the present experiments are essential vectors that transmit many important diseases to humans and domestic pests and have been reported to develop faster resistance to many pesticides, causing unsuccessful control. Thus, it is necessary to determine other control methods. This research using A. galanga to control all three mosquito species, as this plant species is commonly used and easily grown in Thailand, which can reduce the economic cost of production.

Alpinia galanga is a plant belonging to the Zingberaceae family. We chose the rhizome of $A$. galanga for this research because it is easily found and grown in Thailand or other countries in SE Asia; thus, it could probably be used easily throughout the year and provide a low-cost form of mosquito control. This small-scale laboratory experiment aimed to evaluate the effectivity of A. galanga extract used as pesticide. Further research focusing on the application in the environment is indispensable to estimate the economic feasibility.

This plant family has been shown by many reports to have insecticidal activity towards many pests. In the control of mosquitoes, for example, A. galanga essential oils could synergy in the adulticidal efficacy by improvement of permethrin toxicity [6] or repellency effect on $A e$. aegypti adult [29]. Abdullah et al. [1] reported antifeedant, repellent and toxic effects of $A$. galanga rhizomes on Coptotermes gestroi and Coptotermes curvignathus. Rathy et al. [36] also reported $100 \%$ mortality of third-instar larvae of Aedes sp. after $72 \mathrm{~h}$ exposure to A. galanga leaf water distillation extract. Misni et al. [27] described the effectiveness of microencapsulated essential oils of $A$. galanga in lotion formulations against $C x$. quinquefasciatus. Moreover, toxicity of $A$. galanga can be found in larvae stage of other insects such as Spodoptera litura [35] or in Plutella xylostella [9]. Although A. galanga has been shown by many previous reports to have insecticidal activity towards many pests, however, there are no reports yet describing control the isolated compound like trans-cinnamic acid from A. galanga on Ae. aegypti, A. dirus $\mathrm{B}$ and $C x$. quinquefasciatus larvae yet.

In addition, the extraction method used in previous reports was water distillation method or Soxhlet extraction. The extraction method used in this present work is by using soaking method which have main goal to prevent any destruction of compounds inside $A$. galanga no form of external thermal energy. Based on that, a soaking extraction at room temperature was chosen since it is not known which exact compounds inside $A$. galanga are active ones regarding the influence on the metabolism of the targeted mosquito larvae.

Larval stages of mosquitoes were chosen to study in this present work as there are easy targets for pesticides because they breed in water and can be dealt with in this habitat conveniently. The results showed that the control efficiency varied among the A. galanga extracts on mosquito larvae species, with the crude hexane extract having the most active larvicidal effect on all species $(24 \mathrm{~h}$ $\mathrm{LC}_{50} \sim 24-53 \mathrm{ppm}$, Table 2), and $C x$. quinquefasciatus was the most susceptible to the extracts compared to the other species. Thus, A. galanga extract, which has transcinnamic acid as an active ingredient, can control the larvae of all three essential mosquito species. Our results indicated that the crude $A$. galanga hexane extract had higher toxicity than the other crude extracts from the $A$. galanga. However, the toxicity is less than synthetic pesticide like Temephos.

Table 1 Information about the rhizome of $A$. galanga extracts which was extracted sequentially with hexane, dichloromethane, ethyl acetate and methanol by soaking

\begin{tabular}{llll}
\hline Solvent & Weight (g) & Yield $^{\mathbf{a}}$ (\% wt:wt) & Characteristics \\
\hline Hexane & 24.8 & 1.21 & Yellow oil \\
Dichloromethane & 16.00 & 0.80 & Yellow oil \\
Ethyl acetate & 18.94 & 0.95 & Dark brown gum \\
Methanol & 76.85 & 3.84 & Black gum \\
\hline
\end{tabular}

a Weight of crude extract/weight of dried rhizome $\times 100$ 
Table $2 \mathrm{LC}_{50} \pm \mathrm{SE}$ values (PPM) ${ }^{\mathrm{a}}$ of A. galanga extract on Aedes aegypti, Anopheles dirus B and Culex quinquefasciatus larvae

\begin{tabular}{|c|c|c|c|c|c|c|}
\hline \multirow[t]{2}{*}{ Extract $^{b}$} & \multicolumn{2}{|l|}{ Aedes aegypti } & \multicolumn{2}{|c|}{ Anopheles dirus B } & \multicolumn{2}{|c|}{ Culex quinquefasciatus } \\
\hline & $24 \mathrm{~h}$ & $48 \mathrm{~h}$ & $24 \mathrm{~h}$ & $48 \mathrm{~h}$ & $24 \mathrm{~h}$ & $48 \mathrm{~h}$ \\
\hline H & $53.39 \pm 2.27 a b$ & $41.02 \pm 3.56 a$ & $36.11 \pm 4.46 b$ & $17.11 \pm 1.39 b$ & $24.35 \pm 3.78 b$ & $18.39 \pm 1.297 b$ \\
\hline D & $63.49 \pm 5.06 a$ & $42.69 \pm 2.32 a$ & $63.40 \pm 2.50 c$ & $23.66 \pm 2.49 c$ & $41.21 \pm 5.46 c$ & $24.46 \pm 4.12 c$ \\
\hline$E$ & $123.29 \pm 5.91 \mathrm{c}$ & $111.49 \pm 8.76 b$ & $79.35 \pm 5.15 d$ & $52.79 \pm 4.62 d$ & $46.59 \pm 5.11 c$ & $26.45 \pm 4.10 c$ \\
\hline M & $1717.05 \pm 18.49 d$ & $1611.76 \pm 10.49 c$ & $423.06 \pm 9.16 \mathrm{e}$ & $242.21 \pm 3.85 e$ & $127.86 \pm 2.14 d$ & $56.34 \pm 1.45 d$ \\
\hline Cin & $45.54 \pm 4.48 b$ & $37.51 \pm 3.76 a$ & $24.15 \pm 3.78 a$ & $14.96 \pm 1.12 \mathrm{a}$ & $6.74 \pm 0.68 a$ & $7.29 \pm 6.22 \mathrm{a}$ \\
\hline $\mathrm{T}$ & $0.0177 \pm 0.003$ & $0.0200 \pm 0.003$ & $0.003 \pm 0.0001$ & $0.001 \pm 0.0003$ & $0.06 \pm 0.007 e$ & $0.01 \pm 0.007$ \\
\hline
\end{tabular}

a For all experiments, results followed by the same letters within the same column are not significantly different by Tukey's test $(P<0.05)$

b Extracts: $\mathrm{H}$, hexane crude extract; $\mathrm{D}$, dichloromethane crude extract; $\mathrm{E}$, ethyl acetate crude extract; $\mathrm{M}$, methanol crude extract; Cin, trans-cinnamic acid; $\mathrm{T}$, positive control (Temephos)

Table 3 Enzyme activity of surviving mosquito larvae after $24 \mathrm{~h}$ exposure to A. galanga extracts or trans-cinnamic acid

\begin{tabular}{|c|c|c|c|c|c|c|c|c|c|}
\hline \multirow[t]{2}{*}{ Compound $^{c}$} & \multicolumn{3}{|c|}{ Acetylcholinesterase $^{a, b}$} & \multicolumn{3}{|c|}{ Carboxylesterase $^{\mathbf{a}, \mathbf{b}}$} & \multicolumn{3}{|c|}{ Glutathione-S-transferase ${ }^{a, b}$} \\
\hline & Ae. aegypti & A. dirus B & $\begin{array}{l}\text { Cx. } \\
\text { quinquefasciatus }\end{array}$ & Ae. aegypti & A. dirus B & $\begin{array}{l}\text { Cx. } \\
\text { quinquefasciatus }\end{array}$ & Ae. aegypti & A. dirus B & $\begin{array}{l}\text { Cx. } \\
\text { quinquefasciatus }\end{array}$ \\
\hline C & $13.80 \pm 0.01 a$ & $12.72 \pm 0.01 b$ & $13.94 \pm 0.03 c$ & $110.96 \pm 0.12 b$ & $125.10 \pm 0.07 e$ & $107.70 \pm 0.06 \mathrm{e}$ & $2.99 \pm 0.27 a$ & $4.35 \pm 0.39 a$ & $5.60 \pm 0.06 e$ \\
\hline $\mathrm{H}$ & $14.62 \pm 0.06 c$ & $13.46 \pm 0.04 c$ & $15.71 \pm 0.03 e$ & $124.46 \pm 0.07 e$ & $104.47 \pm 0.12 d$ & $85.55 \pm 0.08 d$ & $4.44 \pm 0.40 b$ & $6.21 \pm 0.07 b$ & $5.04 \pm 0.03 e$ \\
\hline D & $15.91 \pm 0.01 d$ & $14.08 \pm 0.02 e$ & $13.67 \pm 0.02 b$ & $112.73 \pm 0.08 c$ & $101.56 \pm 0.05 c$ & $76.02 \pm 0.08 b$ & $5.42 \pm 0.04 \mathrm{e}$ & $6.96 \pm 0.68 b$ & $5.13 \pm 0.01 b$ \\
\hline E & $17.00 \pm 0.01 \mathrm{e}$ & $13.53 \pm 0.01 d$ & $15.23 \pm 0.01 d$ & $117.44 \pm 0.10 \mathrm{~d}$ & $95.74 \pm 0.08 a$ & $72.88 \pm 0.03 a$ & $5.32 \pm 0.04 d$ & $6.21 \pm 0.10 b$ & $5.40 \pm 0.04 d$ \\
\hline M & $22.85 \pm 0.08 f$ & $14.76 \pm 0.01 f$ & $16.52 \pm 0.01 f$ & $108.05 \pm 0.07 a$ & $100.85 \pm 0.03 b$ & $73.82 \pm 0.01 a$ & $6.13 \pm 0.08 f$ & $5.66 \pm 0.11 c$ & $4.91 \pm 0.05 a$ \\
\hline Cin & $13.73 \pm 0.02 b$ & $12.52 \pm 0.02 \mathrm{a}$ & $12.99 \pm 0.04 a$ & $127.91 \pm 0.09 f$ & $104.35 \pm 0.08 d$ & $79.64 \pm 0.06 c$ & $4.93 \pm 0.04 c$ & $12.65 \pm 0.17 \mathrm{~d}$ & $5.53 \pm 0.04 c$ \\
\hline
\end{tabular}

${ }^{a}$ For all experiments, results followed by the same letters within the same column are not significantly different by Tukey's test $(P<0.05)$

b Units of enzymes: Acetylcholinesterase $=\mu \mathrm{M}$ acetylcholinesterase $/ \mathrm{min} / \mathrm{mg}$ of protein; carboxylesterase, $\mathrm{nM} p$-nitrophenol/min $/ \mathrm{mg}$ protein; glutathione-Stransferase, $\mathrm{mM}$ CDNB conjugated product $/ \mathrm{mg}$ protein $/ \mathrm{min}$

c Compounds: C, Comtrol, $\mathrm{H}$, hexane crude extract; D, dichloromethane crude extract; $\mathrm{E}$, ethyl acetate crude extract; $\mathrm{M}$, methanol crude extract; Cin, trans-cinnamic acid

Many investigators have studied the chemistry of galangal rhizome. Scheffer et al. [38] analysed a rhizome sample from Indonesia and reported 1,8-cineole (47.3\%), $\alpha$-pinene (11.5\%), $\beta$-pinene (7.1\%), $\alpha$-thujene (6.2\%), terpinen-4-ol (6.0\%), $\alpha$-terpineol, limonene (4.3\% each) and many other compounds in lesser concentrations. De Pooter et al. [12] analysed a sample from Malaysia and reported (E)-farnesene $(18.2 \%), \beta$-bisabolene (16.2\%), $\alpha$-bergamontene $(10.7 \%)$ and $\alpha$-pinene $(10.2 \%)$ as the important components. Janssen and Scheffer [15] determined that the oil of A. galanga contained 1'-acetoxychavicol acetate, $1^{\prime}$-acetoxyeugenol acetate and $1^{\prime}$-hydroxychavicol acetate as trace constituents.

Our study indicated that the trans-cinnamic acid isolated from A. galanga hexane extract could control thirdinstar mosquito larvae. trans-Cinnamic acid seems to be one of the active ingredients; in this case, this compound is well known and has been reported to be an insecticide to other species. However, this report is the first report on the potential use of trans-cinnamic acid for mosquito control. The present study suggests that $A$. galanga plays a significant role in mosquito larval control, with transcinnamic acid as the active compounds.

Cinnamic acid esters and their derivatives are widely distributed in plants, including cereals, legumes, oilseeds, fruits, vegetables and tea or coffee beverages [8]. Due to their frequent occurrence in plants and low toxicity to humans, animals and the environment [16, 22], cinnamic acid derivatives have attracted many toxicologists. In previous research, cinnamic acid derivatives have been described with actions such as antimicrobial [39], antiinflammatory [10] and pesticidal on Spodoptera littoralis [31].

From Table 3, it seems that carboxylesterase is one of the reasons causing mortality in mosquitoes, especially $A$. dirus $\mathrm{B}$ and $C x$. quinquefasciatus larvae. It is evident that the toxicity in Ae. aegypti is less than that in the other two species, as their detoxification enzymes seem to be significantly induced by some extracts, especially hexane crude extract and cinnamic acid. There is a large amount of research showing that detoxification enzymes play an essential role to chemical pesticide resistance 
and that their levels increase to eliminate pesticides or other xenobiotics from an animal's body. For example, Kaur et al. [19] reported that the induction of detoxification enzyme activities depended on both the duration of treatment and the concentration; prolonged treatment and high dose showed a higher increase in enzyme activities. Zhou et al. [44] showed that extracts from Illicium verum fruit induced EST activity in Myzus persicae and Lymantria dispar after they were fed on a diet of aspen leaves supplemented with phenolic glycosides. Yonggyun et al. [40] and Karuppaiah et al. [18] described insecticide resistance in Spodoptera litura by overexpression of detoxification enzymes. Similarly, in other insect species, Oedaleus asiaticus [13], Amsacta albistriga [26] and Musca domestica [43], cytochrome P450, CE and GST were reported to play roles in the development of chemical pesticides resistance.

Insects including mosquitoes are known for their ability to develop resistances to insecticides. Presently there are insects resistant to every synthetic chemical insecticide used. There are many factors to developing resistance. An insecticide is detoxified by one or more enzymes before it can reach its site of action. Mixed-function oxidases or other enzymes are involved. Most resistance may develop to only a single synthetic insecticide such as organophosphates, carbamates, pyrethroids, neonicotinoids, etc. But, there are so many ingredients in galangal crude extract, plant extract based pesticides. It is not easy to develop themselves to resistance so many compound at the same time.

As pesticides generally act on neural enzymes, the AChE activity analysis showed that the AChE activities in all three species were increased. Observation of the behaviour of the treated larvae clearly showed that they were motionless. Thus, the effect of A. galanga or transcinnamic acid may have another mode of action on neuronal $\mathrm{Na}^{+} / \mathrm{K}^{+}$icon channels or other proteins, which will require further study.

\section{Conclusion}

This is the report to show an effect of A. galanga solvent extracts and trans-cinnamic acid as pesticides on Ae. aegypti, $A$. dirus B and $C x$. quinquefasciatus larvae. Overall, the relationships among detoxification and the acute toxicity of $A$. galanga suggest that the $A$. galanga extracts which has trans-cinnamic acid as active ingredient compound affect the mortality of Ae. aegypti, A. dirus $\mathrm{B}$ and $C x$. quinquefasciatus larvae. Our data will also be useful for generating a database for plant natural pesticidal studies and will be used in the future larger scale for vector control in developing countries, especially in Southeast Asia.
Abbreviations

$\mathrm{RH}$ : relative humidity; CarE: carboxylesterase; GST: glutathione-S-transferase; AChE: acetylcholinesterase; A. galanga: Alpinia galanga; D:L: dark:light; NMR: nuclear magnetic resonance; DMSO: dimethyl sulphoxide; $\mathrm{LC}_{50}$ : median lethal concentrations; EDTA: ethylenediaminetetraacetic acid; pNPA: para-nitrophenyl acetate; CDNB: 1-chloro-2,4-dinitrobenzene; DTNB: Ellman's reagent or 5, 5'-dithiobis (2-nitrobenzoic acid); ASCh: acetylthiocholine iodide.

\section{Acknowledgements}

The authors are grateful and would like to thank Gradute school, Kasetsart university and the funding from the Department of Zoology, Faculty of Science, Kasetsart University. W. P. is grateful to the Center of Excellence for Innovation in Chemistry (PERCH-CIC), Office of the Higher Education Commission, Ministry of Education, for financial support.

\section{Authors' contributions}

VB and WP designed the experiment. AP, TY and WPo performed the experiments. VB and WP wrote and reviewed the paper. All author checked all the details. All authors read and approved the final manuscript.

\section{Funding}

This research was funded by the graduate school and the funding from the Department of Zoology, Faculty of Science, Kasetsart University, and the Center of Excellence for Innovation in Chemistry (PERCH-CIC), Office of the Higher Education Commission, Ministry of Education.

Availability of data and materials

All data are presented in Tables 1, 2, 3

\section{Ethics approval and consent to participate}

All experimental procedures in this research were performed with the approval of an appropriate animal Ethics Committee of Kasetsart University, Thailand.

\section{Consent for publication}

This research has been confirmed for publication in the journal.

\section{Competing interests}

The authors declare that they have no competing interests.

\section{Author details}

${ }^{1}$ Animal Toxicology and Physiology Speciality Research Unit, Department of Zoology, Faculty of Science, Kasetsart University, Phahonyothin Road, Bangkok 10900, Thailand. ${ }^{2}$ Department of Chemistry and Center of Excellence for Innovation in Chemistry, Faculty of Science, and Special Research Unit for Advanced Magnetic Resonance, Kasetsart University, Bangkok 10900, Thailand.

Received: 12 March 2019 Accepted: 10 June 2019

Published online: 02 October 2019

\section{References}

1. Abdullah F, Subramanian P, Ibrahim H, Abdul Malek SN, Lee GS, Hong SL. Chemical composition, antifeedant, repellent, and toxicity activities of the rhizomes of galangal, Alpinia galanga against asian subterranean termites, Coptotermes gestroi and Coptotermes curvignathus (Isoptera: Rhinotermitidae). J Insect Sci. 2015;15(1):7. https://doi.org/10.1093/jisesa/ ieu175.

2. Arshia H, Sook YL, Wei LC, Mohd A, Vannajan L, Khalijah A. Inhibition and larvicidal activity of phenylpropanoids from Piper sarmentosum on acetylcholinesterase against mosquito vectors and their binding mode of interaction. PloS One. 2016;11:e0155265. https://doi.org/10.1371/journal. pone.0155265.

3. Bassolé IH, Guelbeogo WM, Nébié R, Costantini C, Sagnon N, Kabore Zl, Traoré SA. Ovicidal and larvicidal activity against Aedes aegypti and Anopheles gambiae complex mosquitoes of essential oils extracted from three spontaneous plants of Bukina Faso. Parasitologia. 2003;45:23-6. 
4. Bradford MM. A rapid and sensitive method for the quantitation of microgram quantities of protein utilizing the principle of protein-dye binding. Anal Biochem. 1976;72:248-54.

5. Chansang U, Zahiri NS, Bansiddhi J, Boonruad T, Thongsrirak P, Mingmuang J, Benjapong N, Mulla MS. Mosquito larvicidal activity of aqueous extracts of long pepper (Piper retrofractum Vahl) from Thailand. J Vector Ecol. 2005;30(2):195-200.

6. Chansang A, Champakaew D, Junkum A, Jitpakdi A, Amornlerdpison D, Kongdee AA, Riyong D, Wannasan A, Intirach J, Muangmoon R, Pitasawat B. Synergy in the adulticidal efficacy of essential oils for the improvement of permethrin toxicity against Aedes aegypti L. (Diptera: Culicidae). Parasite Vectors. 2018;11:417.

7. Choochote W, Chaiyasit D, Kanjanapothi D, Rattanachanpichai E, Jitpakdi A, Tuetun B, Pitasawat B. Chemical composition and anti-mosquito potential of rhizome extract and volatile oil derived from Curcuma aromatica against Aedes aegypti (Diptera: Culicidae). J Vector Ecol. 2005;30:302-9.

8. Clifford NM. Chlorogenic acids and other cinnamates-nature, occurrence, dietary burden, absorption, and metabolism. J Sci Food Agric. 2000:80:1033-43.

9. Dadang S, Riyanto S, Ohsawa K. Lethal and antifeedant substance from rhizome of Alpinia galanga Sw. (Zingiberaceae). J Pestic Sci. 1998;23(3):304-7.

10. Debnath B, Samanta S, Roy K, Jha TQSAR. Study on some p-arylthio cinnamides as antagonists of biochemical ICAM-1/LFA-1 interaction and ICAM-1/JY-8 cell adhesion in relation to anti-inflammatory activity. Bioorg Med Chem. 2003;11:1615-9.

11. Delfino RT, Ribeiro TS, Figueroa-Villar JD. Organophosphorus compounds as chemical warfare agents: a review. J Braz Chem Soc. 2009;20:407-28.

12. DePooter HL, Nor Omar M, Coolsaet BA, Schamp NM. The essential oil of greater galanga (Alpinia galanga) from Malaysia. Phytochemistry 1985;24:93-96.

13. Dong W, Zhang X, Zhang X, Wu H, Zhang M, Ma E, Zhang J. Susceptibility and potential biochemical mechanism of Oedaleus asiaticus to beta-cypermethrin and deltamethrin in the Inner Mongolia, China. Pestic Biochem Physiol. 2016;132:47-52.

14. Ellman GL, Courtney KD, Andres VJ, Feather-Stone RM. A new and rapid colorimetric determination of acetylcholinesterase activity. Biochem Pharmacol. 1961;7:88-95.

15. Janssen AM, Scheffer JJC. Acetoxychavicol acetate, an antifungal component of alpinia galanga. Planta Med. 1985;6:507-11.

16. Hoskins JA. The occurrence, metabolism, and toxicity of cinnamic acid and related compounds. J Appl Toxicol. 1984;4:283-92.

17. Kalinowska M, Świsłocka R, Lewandowski W. The spectroscopic (FT-IR, FTRaman, and ${ }^{1} \mathrm{H}-{ }^{13} \mathrm{C}-\mathrm{NMR}$ ) and theoretical studies of cinnamic acid and alkali metal cinnamates. J Mol Struct. 2007;834-836:572-80.

18. Karuppaiah V, Srivastava C, Padaria JC, Subramanian S. Quantitative changes of the carboxylesterase associated with pyrethroid susceptibility in Spodoptera litura (Lepidoptera: Noctuidae). Afr Entomol. 2017;25:175-82.

19. Kaur A, Sohal SK, Arora S, Kaur H, Kaur AP. Effect of plant extracts on biochemistry of Bactrocera cucurbitae (Coquillett). J Entomol Zool Stud. 2014;2(3):86-92.

20. Kiran RS, Bhavani K, Devi SP, Rao RBR, Reddy JK. Composition and larvicidal activity of leaves and stem essential oils of Chloroxylon swietenia DC. against Aedes aegypti and Anopheles stephensi. Bioresour Technol. 2006:97:2481-4.

21. Koou SY, Chong CS, Vythilingam I, Lee CY, Ng LC. Insecticide resistance and its underlying mechanisms in field populations of Aedes aegypti adults (Diptera: Culicidae) in Singapore. Parasit Vect. 2014;7:471. https:// doi.org/10.1186/s13071-014-0471-0.

22. Lafay S, Gil-Izquierdo A. Bioavailability of phenolic acids. Phytochem Rev. 2008;7:301-11.

23. Lee HS. Mosquito larvicidal activity of aromatic medicinal plant oils against Aedes aegypti and Culex pipiens pallens. J Am Mosquito Control Assoc. 2006:22:292-5.

24. Marcombe S, Mathieu RB, Pocquet N, Riaz MA, Poupardin R, Sélior S, Darriet F, Reynaud S, Yébakima A, Corbel V, David JP, Chandre F. Insecticide resistance in the dengue vector Aedes aegypti from Martinique: distribution, mechanisms and relations with environmental factors. PLoS One. 2012;7(2):e30989. https://doi.org/10.1371/journal.pone.0030989
25. Melo-Santos MA, Varjal-Melo JJ, Araújo AP, Gomes TC, Paiva MH, Regis LN, Furtado AF, Magalhaes T, Macoris ML, Andrighetti MT, Ayres CF. Resistance to the organophosphate temephos: mechanisms, evolution and reversion in an Aedes aegypti laboratory strain from Brazil. Acta Trop. 2010;113(2):180-9. https://doi.org/10.1016/j.actatropica.2009.10.015.

26. Muthusamy R, Shivakumar MS. Resistance selection and molecular mechanisms of cypermethrin resistance in red hairy caterpillar (Amsacta albistriga walker). Pestic Biochem Physiol. 2015;117:54-61.

27. Misni N, Nor ZM, Ahmad R. Repellent effect of microencapsulated essential oil in lotion formulation against mosquito bites. J Vector Borne Dis. 2017;54(1):44-53.

28. Nardi F, Frati F, Romani R, ROSI G, Corsi I, Focardi S. Organophosphateresistant acetylcholinesterase in Mytilus galloprovincialis: identification of a resistance Ace gene in cerebral ganglion, gills and adductor muscle. Comp Biochem Physiol A Mol Integr Physiol. 2008;151(1 Supplement):S6

29. Misni N, Nor ZM, Ahmad R. New candidates for plant-based repellents against Aedes aegypti. J Am Mosquito Control Assoc. 2016;32(2):117-23.

30. Oppenoorth FJ, Van der Pas LJT, Houx NWH. Glutathione S-transferases and hydrolytic activity in a tetrachlorvinphos- resistant strain of housefly and their influence on resistance. Pestic Biochem Physiol. 1979;1 1:176-88.

31. Pandji C, Grimm C, Wray V, Witte L, Proksch P. Insecticidal constituents from four species of the Zingiberaceae. Phytochemistry. 1993;34(2):415-9.

32. Phankaen Y, Manaprasertsak A, Pluempanupat W, Koul O, Kainoh Y, Bullangpoti V. Toxicity and repellent action of Coffea arabica against Tribolium castaneum (Herbst) adults under laboratory conditions. J Stored Prod Res. 2017;71:112-8.

33. Pluempanupat S, Kumrungsee N, Pluempanupat W, Ngamkitpinyo K, Chavasiri W, Bullangpoti V, Koul O. Laboratory evaluation of Dalbergia oliveri (Fabaceae: Fabales) extracts and isolated isoflavonoids on Aedes aegypti (Diptera: Culicidae) mosquitoes. Ind Crops Prod. 2013;44:653-8.

34. Prajapati V, Tripathi AK, Aggarwal KK, Khanuja S. Insecticidal, repellent and oviposition-deterrent activity of selected essential oils against Anopheles stephensi, Aedes aegypti and Culex quinquefasciatus. Biores Technol. 2005;96:1749-57.

35. Pumchan A, Puangsomchit A, Temyarasilp P, Pluempanupat W, Bullangpoti . Bioinsecticidal activity of Alpinia galanga (L.) on larval development of Spodoptera litura (Lepidoptera: Noctuidae). Commun Agric Appl Biol Sci. 2015;80(2):179-86.

36. Rathy MC, Sajith U, Harilal CC. Plant diversity for mosquito control: a preliminary study. Int J Mosquito Res. 2015;2(1):29-33.

37. Senthilkumar A, Kannathasan K, Venkatesalu V. Chemical constituents and larvicidal property of the essential oil of Blumea mollis (D. Don) Merr. Against Culex quinquefasciatus. Parasitol Res. 2008;103:959-62.

38. Scheffer JJC, Gani A, Baerheim Svendsen A. Monoterpenes in the essential rhizome oil of Alpinia galanga (L.). Willd Sci Pharm 1981;49:337-46.

39. Sova M. Antioxidant and antimicrobial activities of cinnamic acid derivatives. Mini Rev Med Chem. 2012;12:749-67.

40. Yonggyun K, Cho JR, Lee J, Kang S, Han SC, Hong KJ, Kim HS, Yoo JK, Lee JO. Insecticide resistance in the tobacco cutworm, Spodoptera litura (Fabricius) (Lepidoptera: Noctuidae). J Asia Pac Entomol. 1998;1:115-22.

41. Worek F, Wille T, Koller M, Thiermann $\mathrm{H}$. Reactivation kinetics of a series of related bispyridinium oximes with organophosphate-inhibited human acetylcholinesterase - Structure-activity relationships. Biochem Pharmacol. 2012;83(12):1700-6

42. World Health Organization (WHO). Instruction for determining the susceptibility or resistance of mosquito larvae to insecticides. Mimeographed Document, WHO/NBC/. 81.807; 1981.

43. Zhang L, Shi J, Shi X, Liang P, Gao J, Gao X. Quantitative and qualitative changes of the carboxylesterase associated with beta-cypermethrin resistance in the housefly, Musca domestica (Diptera: Muscidae). Comp Biochem Physiol Part B Biochem Mol Biol Int J. 2010;156:6-11.

44. Zhou BG, Wang S, Dou TT, Liu S, Li MY, Hua RM, Li SG, Lin HF. Aphicidal activity of Illicium verum fruit extracts and their effects on the acetylcholinesterase and glutathione s-transferases activities in Myzus persicae (Hemiptera: Aphididae). J Insect Sci. 2016;16(1):11.

\section{Publisher's Note}

Springer Nature remains neutral with regard to jurisdictional claims in published maps and institutional affiliations. 